\title{
Coding space-time stimulus dynamics in auditory brain maps
}

\author{
Yunyan Wang ${ }^{1}$, Yoram Gutfreund ${ }^{2}$ and José L. Peña ${ }^{1 *}$ \\ ${ }^{1}$ Dominick P. Purpura Department of Neuroscience, Albert Einstein College of Medicine, Bronx, NY, USA \\ ${ }^{2}$ The Rappaport Research Institute and Faculty of Medicine, The Technion, Haifa, Israel
}

\section{Edited by: \\ Catherine Carr, University of \\ Maryland, USA}

Reviewed by:

Guangying Wu, The George Washington University, USA

Hermann Wagner, RWTH Aachen

University, Germany

*Correspondence:

José L. Peña, Albert Einstein

College of Medicine, Rose Kennedy

Center 529, 1300 Morris Park Ave.

Bronx, NY 10461, USA

e-mail: jose.pena@einstein.yu.edu
Sensory maps are often distorted representations of the environment, where ethologically-important ranges are magnified. The implication of a biased representation extends beyond increased acuity for having more neurons dedicated to a certain range. Because neurons are functionally interconnected, non-uniform representations influence the processing of high-order features that rely on comparison across areas of the map. Among these features are time-dependent changes of the auditory scene generated by moving objects. How sensory representation affects high order processing can be approached in the map of auditory space of the owl's midbrain, where locations in the front are over-represented. In this map, neurons are selective not only to location but also to location over time. The tuning to space over time leads to direction selectivity, which is also topographically organized. Across the population, neurons tuned to peripheral space are more selective to sounds moving into the front. The distribution of direction selectivity can be explained by spatial and temporal integration on the non-uniform map of space. Thus, the representation of space can induce biased computation of a second-order stimulus feature. This phenomenon is likely observed in other sensory maps and may be relevant for behavior.

Keywords: sound localization, adaptation, center-surround, acoustic motion, direction selectivity, maps
Here we consider the emergence of tuning to temporally-dynamic stimulus features underlying motion selectivity in the owl's external nucleus of the inferior colliculus (ICx). Tuning in ICx displays a topography that corresponds with spatial coordinates (Knudsen and Konishi, 1978a). This map allows approaching ICx as a "retina" for auditory space. Thus, reverse-correlation methods such as the white-noise stimulation used by studies in vision (Chichilnisky, 2001; Recio-Spinoso et al., 2005) can be adapted to assess the selectivity of neurons to spatially-dynamic features of the auditory scene.

Motion detection requires integration over space and time. Below, we first examine integration over space, in the centersurround interactions of spatial receptive fields, and over time, in the history-dependent response properties of single cells. Subsequently, we address how the map topography influences tuning across the population. We conclude by discussing functional implications for coding acoustic motion direction.

\section{SURROUND SUPPRESSION IN AUDITORY SPATIAL RECEPTIVE FIELDS}

Experimental evidence is consistent with surround suppression in ICx (Knudsen and Konishi, 1978b; Fujita and Konishi, 1991). Topography within ICx allows the formation of lateral connections that correspond to neighboring relationships in auditory space. Recently, Wang et al. (2012) showed that simultaneous stimulation of the receptive-field center and surround of ICx neurons could result in up to $50 \%$ attenuation of response at the center compared to when the center was stimulated alone. This study used white-noise stimulation from concurrent random locations to measure the equivalent of the classical and extra-classical receptive fields in vision (Marmarelis and McCann, 1973; Chichilnisky, 2001; Recio-Spinoso et al., 2005) in space-specific neurons of ICx (Figures 1A,B). Surround suppression had a sharpening effect on spatial tuning at the center (Figure 1C), consistent with the narrowing of receptive fields observed using multiple concurrent sound sources (Bremen and Middlebrooks, 2013).

There is strong evidence that local GABAergic inhibition mediates surround suppression in sensory systems (Cook and McReynolds, 1998; Bloomfield and Xin, 2000; Völgyi et al., 2002; Sohn and Hallett, 2004; Foeller et al., 2005). Surround suppression is consistent with the sharpened spatial tuning in ICx during white noise stimulation (Wang et al., 2012), and with the broadening of tuning after the application of GABA antagonists (Fujita and Konishi, 1991; Mori, 1997; Zheng and Knudsen, 1999, 2001). It is also possible that GABA-mediated lateral inhibition in space originates upstream to ICx. In the avian auditory pathway, ICx is not the first stage in the pathway where localization cues are represented topographically. ITD, the primary cue for azimuth direction in barn owls, is mapped in the nucleus laminaris (Carr and Konishi, 1988, 1990; Carr and Boudreau, 1993; Carr et al., 2013), which projects topographically to the inferior colliculus (IC; Knudsen, 1983; Takahashi et al., 1984, 1989; Takahashi and Konishi, 1988; Carr and Boudreau, 1991). GABAergic transmission is conspicuously present at locations where spatial cues are encoded (Carr et al., 1989; Burger et al., 2005; Lu et al., 2005). Further, feedback connections may mediate 


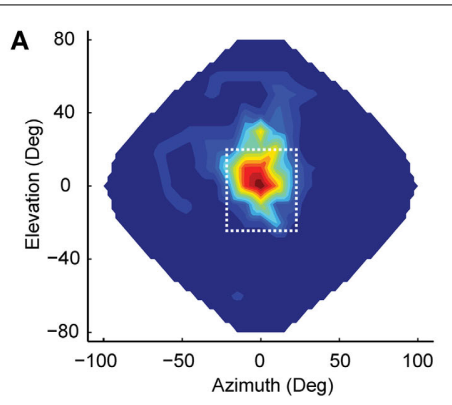

B

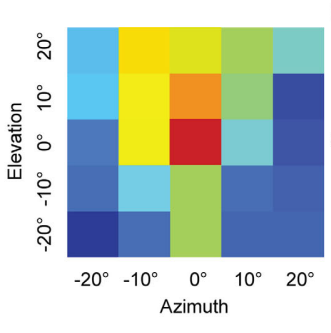

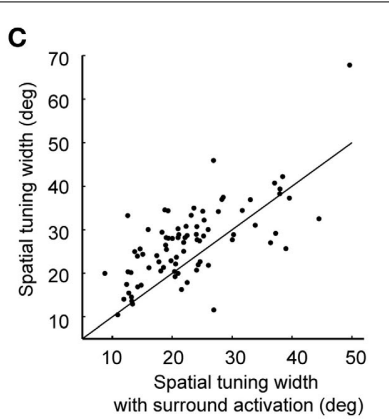

FIGURE 1 | Surround suppression in ICx. (A) Example spatial receptive field of an ICx neuron. Firing rates were interpolated across 144 speakers covering frontal space. The dotted line indicates the area shown in (B). (B) A subset of speakers was used to analyze the center-surround receptive field with white noise stimulation. Each colored box represents the cell's response to a speaker location. The receptive field showed excitation at the center flanked by suppression. (C) Surround activation sharpens the spatial tuning. For most cells ( $n=81$ ), the width of spatial-tuning curves was narrower when both center and surround were stimulated (points above the unity line) compared to when only the center was stimulated. Modified from Wang et al. (2012). surround suppression (Burger and Pollak, 2001). There are pointto-point projections from the optic tectum (OT) to the ICx involved in visual calibration of the auditory map (Luksch et al., 2000; Hyde and Knudsen, 2001, 2002). Lateral inhibition in OT could be carried back to ICx through these connections. Finally, recent evidence suggests that glycinergic inhibition may also play an important role in sound localization, and potentially could contribute to surround suppression (Kuo et al., 2009; Coleman et al., 2011; Fischl et al., 2013).

Mechanisms other than inhibitory projections may induce surround suppression in the auditory pathway. Because sound localization using ITD is based on cross-correlation (Blauert, 1997; Fischer et al., 2008), decreasing interaural correlation reduces the response (Albeck and Konishi, 1995; Saberi et al., 1998; Coffey et al., 2006). Interaural correlation is affected by the number of simultaneous sound sources from different locations and by the properties of the acoustic space (Blauert, 1997). A complex auditory scene can thus induce binaural decorrelation and decrease response when the surround is stimulated. However, decorrelation could not explain the asymmetry in surround suppression observed in Wang et al. (2012).

\section{HISTORY-DEPENDENT RESPONSE: ADAPTATION IN ICx}

Motion detection requires that the neural computation captures changes in location over time. Previously established motion detection models based on lateral excitation and inhibition meet this requirement (Hassenstein and Reichardt, 1958; Torre and Poggio, 1978). On the other hand, adaptation could also constitute a means for spatial integration over time, where the recovery time constitutes the duration of the "memory" in the system (Ulanovsky et al., 2004; Gutfreund and Knudsen, 2006). Similar to nuclei upstream to $\mathrm{ICx}$, in the lateral shell and core of the inferior colliculus (Gutfreund and Knudsen, 2006; Singheiser et al., 2012), ICx neurons show adaptation that recovers in hundreds of milliseconds (Figure 2; Gutfreund and Knudsen, 2006; Wang and Pena, 2013). Recovery time from adaptation generally increases along the auditory pathway from tens of milliseconds in the auditory nerve (Harris

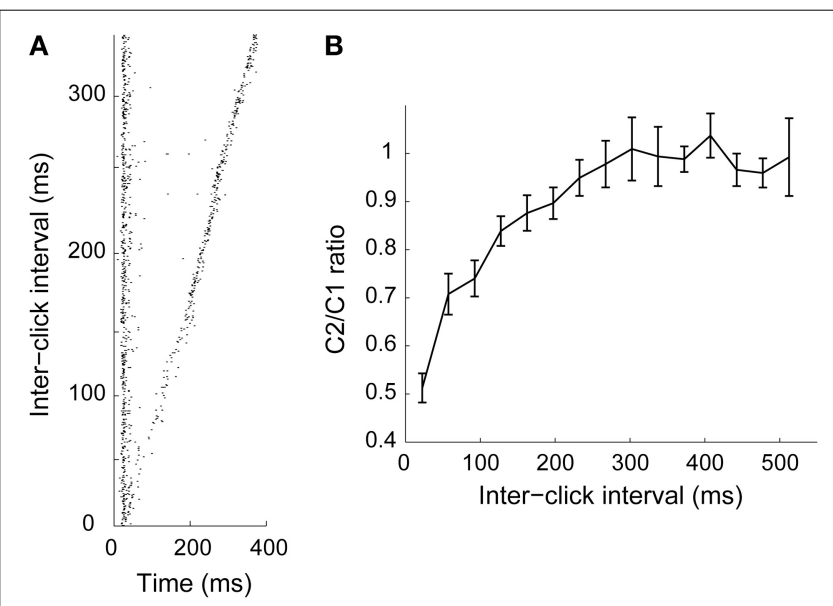

FIGURE 2 | Adaptation time course in ICx. (A) Pairs of 1 ms clicks (C1 and C2) presented at various inter-click intervals. When the onset of the two clicks was close in time, response to the second click decreased relative to the first one. (B) Ratio between responses to $\mathrm{C} 1$ and $\mathrm{C} 2$ as a function of inter-stimulus interval ( $n=44)$. Response to C2 was significantly attenuated when the interval was less than 300 ms. From Wang and Pena (2013).

and Dallos, 1979; Relkin and Turner, 1988) to hundreds of milliseconds in IC (Gutfreund and Knudsen, 2006; Netser et al., 2011; Singheiser et al., 2012), thalamus (Wehr and Zador, 2005) and the auditory cortex (Brosch and Schreiner, 1997; Ulanovsky et al., 2004; Wehr and Zador, 2005; Nelson et al., 2009). It has been suggested that the long time scale of adaptation plays a role in multisensory integration (Gutfreund and Knudsen, 2006), by permitting convergence of sensory modalities processed at different latencies (Bergan and Knudsen, 2009).

Several studies have alluded to synaptic depression as the underlying mechanism for the slow component in the recovery time from adaptation (Ulanovsky et al., 2004; Wehr and Zador, 2005; Gutfreund and Knudsen, 2006). Synaptic depression due to slowly re-activating T-type calcium channels has been demonstrated to play a role in forward suppression lasting several 
$100 \mathrm{~ms}$ (Bayazitov et al., 2013). Intracellular studies in the avian brainstem showed that short-term depression is prevalent in the auditory pathway (Kuba et al., 2002; Cook et al., 2003; MacLeod and Carr, 2007; MacLeod et al., 2007; MacLeod, 2011). In the context of spike-frequency adaptation, particular attention has been paid to intrinsic mechanisms that could result in long-lasting suppression (Benda and Herz, 2003; Gollisch and Herz, 2004; Ingham and McAlpine, 2004). In models of the IC, after hyperpolarization currents mediated by calcium-gated potassium channels have successfully predicted response to time-dynamic binaural stimuli. The rodent IC shows six distinct cell types, each exhibiting unique potassium currents, including delayed-rectifier and calcium-dependent K+ channels (Bond et al., 1999; Stocker and Pedarzani, 2000; Sivaramakrishnan and Oliver, 2001; Womack and Khodakhah, 2003). Additional mechanisms resulting in slow recovery of fast sodium channels have been suggested in models of adaptation, such as voltage dependent, high threshold potassium currents and voltage-dependent potassium channels (M-type) (Cai et al., 1998a,b; Benda and Herz, 2003).

Stimulus-specific adaptation (SSA), an adaptation to the stimulus history and not the history of activation (Ulanovsky et al., 2004; Briley and Krumbholz, 2013) has been observed in the ICx for sounds of different frequencies (Reches and Gutfreund, 2008); however, SSA was not observed in the ICx when spatial cues were tested (Gutfreund and Knudsen, 2006; Reches and Gutfreund, 2008; Netser et al., 2011). The mechanism of SSA has not been conclusively elucidated, although synaptic mechanisms have been implicated (Ulanovsky et al., 2004).

If the response varies at different locations around the receptive-field center, i.e., spatial receptive fields are asymmetric, neurons can more strongly adapt stimuli in one direction than another, leading to selectivity for motion-direction. Unlike surround suppression, adaptation could induce direction selectivity in space-specific neurons that are not topographically arranged, as only receptive field asymmetry is required (Ingham et al., 2001). In support of this idea, ICx cells with asymmetrical spatial receptive fields were direction selective (Figure 3A) and their responses during sound motion could be predicted by the shape of the receptive field and their adaptation properties (Wang and Pena, 2013). At the population level, there was a direct relationship between receptive field asymmetry and the degree of direction selectivity (Figure 3B; Wang and Pena, 2013). The response to moving sounds at different velocities represents further evidence in support of adaptation. Directionality is stronger for fast moving sounds where short intervals between sounds at different locations induced robust adaptation (Wagner and Takahashi, 1992; Wang and Pena, 2013). Hence, neurons displaying response adaptation and asymmetric receptive fields automatically became direction selective without invoking network mechanisms for motion detection (Hassenstein and Reichardt, 1958; Barlow and Levick, 1965).

\section{EFFECT OF MAP DISTORTIONS ON COMPUTATIONS}

Ramon y Cajal first proposed topographic organization was more metabolically efficient for wiring neural representations that mirrored the environment (Cajal, 1999). Maps are convenient for integrating over space and time since stimulus-driven activity

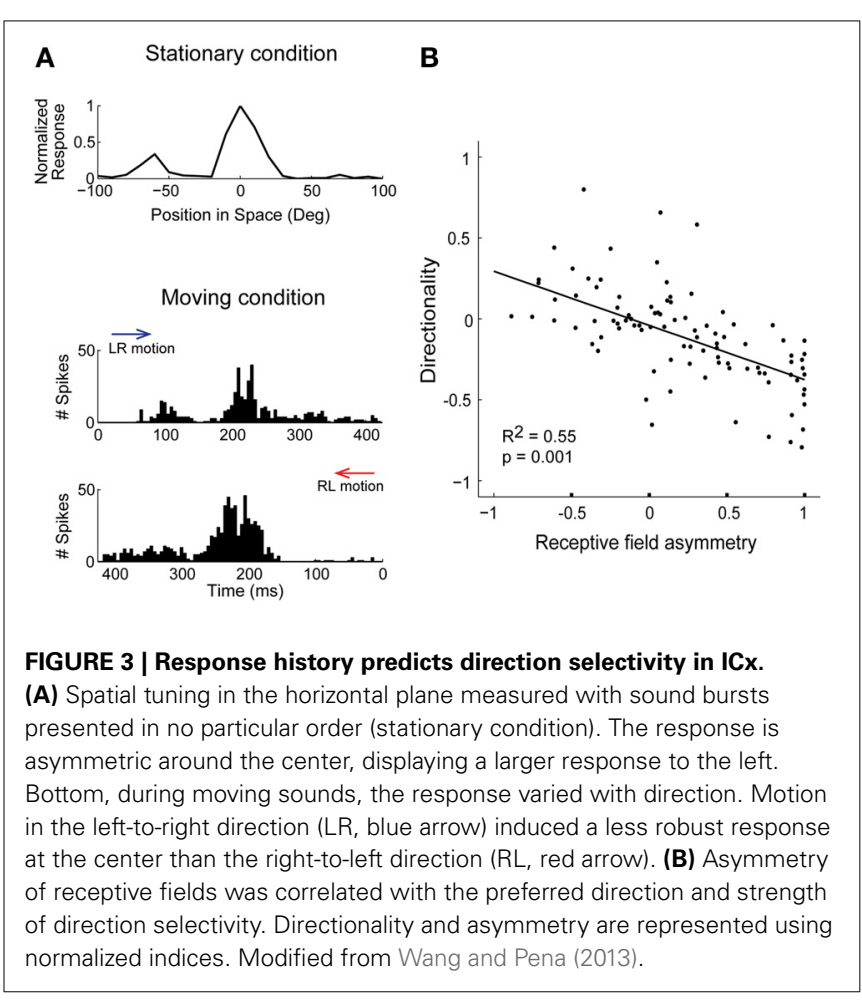

varies systematically across the map in both dimensions. In the rat barrel cortex, local lateral connections are required for temporal coordination of whisking kinematics (Gao et al., 2003). In vision, computation of contrast and direction is also based on local connections (Barlow and Levick, 1965; Bloomfield and Xin, 2000; Völgyi et al., 2002; Zhou and Lee, 2008). Recent work showed that manipulating the spatial pattern of excitation within V1 can distort processing of visual shapes (Michel et al., 2013), indicating topography is exploited in processing high-level features.

In the auditory sensory modality, maps of space are found in close proximity to areas where motor output of orienting behaviors originate, such as in the brachium of the IC and the superior colliculus in mammals (Schnupp and King, 1997; Slee and Young, 2013) and in the ICx and OT in birds (Knudsen and Konishi, 1978a; Knudsen, 1982). A map of auditory space may be useful for multisensory integration, such as in the avian OT (Knudsen, 1982; Hyde and Knudsen, 2001) and mammalian SC (King et al., 1988; Doubell et al., 2000), where visual and auditory spaces are aligned. Coherence between auditory and visual maps may also be important during development, when visual experience can strongly modulate the topography of the auditory map in SC (King, 1999) and OT (Knudsen, 2002).

A common feature of neural maps is the distortion of the representation relative to the real world. Well-known examples include the over-represented visual fovea and the disproportionate homunculus in the somatosensory system, where ethologically important stimulus ranges are magnified in the brain (Penfield and Rasmussen, 1950; Azzopardi and Cowey, 1993). While these distortions may reflect the distribution of sensory afferents from the periphery, they often obey a hierarchy of sensitivity and discriminability requirements. In the ICx and OT 


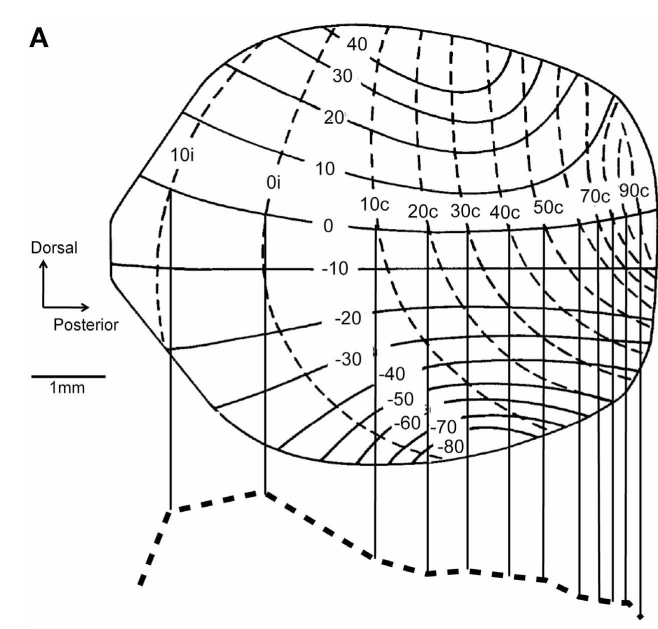

Front
B

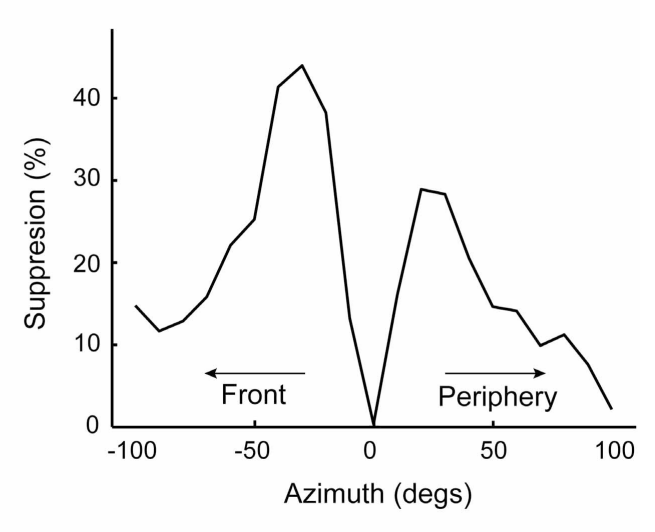

tuned to $20^{\circ}$ in the contralateral hemifield. The center of the receptive field is aligned to $0^{\circ}$ on the $x$-axis. Suppression from frontal space (percent suppression from average response at the center) is stronger than from the periphery. Modified from Wang et al. (2012). maps of barn owls, locations in the front and below eye levels are over-represented (Figure 4A; Knudsen and Konishi, 1978a; Knudsen, 1982). This mapping may reflect orienting behavior, as owls face the target during pursuit (Payne, 1971; Hausmann et al., 2008) and descend from a height to capture prey (Volman, 1994). Distortions on the sensory surface are also consistent with the notion that space maps may represent a "place-coded probability distribution" (Knudsen et al., 1987; Fischer and Peña, 2011).

If there are more neurons representing the front, lateral connections coming from these cells could influence the response of neurons tuned to the periphery. Thus, the distortion in the ICx map could translate into a biased tuning at the population level. This was in fact the case; center-surround receptive fields showed a population bias where suppression from the front was stronger (Wang et al., 2012). The suppressive effect of peripherally-tuned cells was relatively weak on neurons tuned to the front. This bias in surround suppression resulted in a preference of ICx neurons for sounds approaching the front, since suppression is relatively weak in this direction (Figure 4B). Thus, receptive field shape and directional preference depended on tuning eccentricity in $\mathrm{ICx}$, in a manner consistent with the distortions in the spatial map.

Space-specific neurons are commonly observed in the visual (Barlow and Levick, 1965; Hubel and Wiesel, 1974; Knudsen, 1982; Krapp and Hengstenberg, 1996), auditory (Knudsen and Konishi, 1978a; Brugge et al., 1994; Zhou and Wang, 2012) and somatosensory (Mountcastle, 1957; Simons, 1978) systems. Several of these regions are topographically-organized, nonuniform and exhibit center-surround receptive fields (Barlow et al., 1964; Livingstone, 1998; Drew and Feldman, 2007), as in the owl's ICx. Thus, biases in emergent responses that rely on center-surround integration may be a general property of sensory systems.

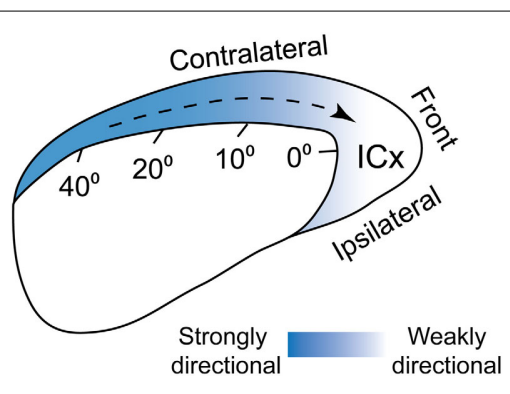

FIGURE 5 | Population-wide directional preference in ICx. ICx neurons prefer sounds moving toward frontal space. This bias in directional preference is stronger for cells tuned to peripheral space and could be mediated both by biased surround suppression and adaptation. From Wang and Pena (2013).

\section{ENCODING SOUND MOTION}

Direction selective neurons have been reported in the mammalian (Sovijarvi and Hyvarinen, 1974; Rauschecker and Harris, 1989; Ahissar et al., 1992; Stumpf et al., 1992; Toronchuk et al., 1992; Wilson and O'Neill, 1998; Ingham et al., 2001) and avian auditory systems (Wagner and Takahashi, 1990, 1992; Wang et al., 2012). However, whether acoustic motion is encoded separately from other features has not been elucidated. We described above two mechanisms, surround suppression and adaptation, which explained a preference for sounds approaching the front. In both cases, the preference became stronger for cells tuned to peripheral space (Figure 5). These mechanisms take effect at different spatial scales relative to the neurons' receptive fields. The effect of surround suppression was strongest in the receptive field troughs flanking the center, where cells do not normally respond. On the other hand, the suppressive effects induced by response 
history were elicited by stimulation further away from the center $\left(40-80^{\circ}\right)$. Although the underlying mechanisms are different, they both induce preference for the same direction (Wang et al., 2012; Wang and Pena, 2013). Thus, these mechanisms could work synergistically to convey directional preference for sounds entering frontal space.

A topography of direction selectivity overlapping the map of auditory space indicates that neural activity in ICx carries information about both the location and the direction of the motion of sounds. This leads us to suggest that both location and motion direction appear represented in the owl's midbrain. However, whether direction and location are decoded independently remains to be demonstrated. Evidence from human EEG suggest that they are processed separately (Ducommun et al., 2002).

The emergence of motion-direction topography in ICx was supported by two principles. First, surround suppression was biased, such that neurons selective for frontal locations more strongly suppressed neurons at peripheral locations. This could be achieved by the non-uniform representation of space (Wang et al., 2012). Second, spatial receptive fields displayed systematic asymmetry in order for adaptation to induce topographicallyorganized direction selectivity. A likely mechanism for this asymmetry is that gain at frontal locations is higher due to the filtering properties of the head (Keller et al., 1998). Direction-dependent gain could induce a stronger response at the front, making receptive field asymmetry that is correlated with spatial tuning (Wang and Pena, 2013). Further, cortical auditory spatial receptive fields are often broad and complex (Brugge et al., 1996; Jenison et al., 2001; Mrsic-Flogel et al., 2005; Zhou and Wang, 2012), which could provide the asymmetry necessary to induce direction selectivity via adaptation.

\section{CONCLUSIONS}

We showed that topography can result in computational biases within neural maps. Neurons at different locations in ICX responded depending on contextual excitation in space and their response history. These mechanisms elicited selectivity for higherorder stimulus properties such as time-dependent stimulus location. Because lateral interactions, adaptation and non-uniform maps are general properties of sensory maps, these processes are likely present in other sensory modalities.

Biased direction-selectivity may be important for detecting auditory looming objects (Maier and Ghazanfar, 2007) or estimating time to collision (Peron and Gabbiani, 2009). Our findings address the salience of sounds moving toward the front. From the viewpoint of coding strategy, the front is where spatial acuity (Knudsen et al., 1979) and signal intensity gain (Keller et al., 1998) are highest. Behaviorally, the owl places its target in the front during pursuit (Payne, 1971; Edut and Eilam, 2004; Hausmann et al., 2008; Ohayon et al., 2008). The preference for sounds moving inward could enhance the orienting response to stimuli entering the most sensitive region for sound localization. In general, directional biases in tuning to stimulus temporal dynamics may be adaptive for more efficient implementation of ethologically-relevant behaviors.

\section{REFERENCES}

Ahissar, M., Ahissar, E., Bergman, H., and Vaadia, E. (1992). Encoding of soundsource location and movement: activity of single neurons and interactions between adjacent neurons in the monkey auditory cortex. J. Neurophysiol. 67, 203-215.

Albeck, Y., and Konishi, M. (1995). Responses of neurons in the auditory pathway of the barn owl to partially correlated binaural signals. J. Neurophysiol. 74, 1689-1700.

Azzopardi, P., and Cowey, A. (1993). Preferential representation of the fovea in the primary visual cortex. Nature 361, 719-721. doi: 10.1038/361719a0

Barlow, H. B., Hill, R. M., and Levick, W. R. (1964). Retinal ganglion cells responding selectively to direction and speed of image motion in the rabbit. J. Physiol. $173,377-407$.

Barlow, H. B., and Levick, W. R. (1965). The mechanism of directionally selective units in rabbit's retina. J. Physiol. 178, 477-504.

Bayazitov, I. T., Westmoreland, J. J., and Zakharenko, S. S. (2013). Forward Suppression in the auditory cortex is caused by the Cav3.1 calcium channel-mediated switch from bursting to tonic firing at thalamocortical projections. J. Neurosci. 33, 18940-18950. doi: 10.1523/JNEUROSCI.333513.2013

Benda, J., and Herz, A. V. M. (2003). A universal model for spike-frequency adaptation. Neural Comput. 15, 2523-2564. doi: 10.1162/0899766033223 85063

Bergan, J. F., and Knudsen, E. I. (2009). Visual modulation of auditory responses in the owl inferior colliculus. J. Neurophysiol. 101, 2924-2933. doi: 10.1152/jn.91313.2008

Blauert, J. (1997). Spatial Hearing: The Psychophysics of Human Sound Localization. Cambridge, MA: MIT Press.

Bloomfield, S. A., and Xin, D. (2000). Surround inhibition of mammalian AII amacrine cells is generated in the proximal retina. J. Physiol. 523(Pt 3), 771-783. doi: 10.1111/j.1469-7793.2000.t01-1-00771.x

Bond, C. T., Maylie, J., and Adelman, J. P. (1999). Small-conductance calciumactivated potassium channels. Ann. N.Y. Acad. Sci. 868, 370-378. doi: 10.1111/j.1749-6632.1999.tb11298.x

Bremen, P., and Middlebrooks, J. C. (2013). Weighting of spatial and spectrotemporal cues for auditory scene analysis by human listeners. PLoS ONE 8:e59815. doi: 10.1371/journal.pone.0059815

Briley, P. M., and Krumbholz, K. (2013). The specificity of stimulus-specific adaptation in human auditory cortex increases with repeated exposure to the adapting stimulus. J. Neurophysiol. 110, 2679-2688. doi: 10.1152/jn.010 15.2012

Brosch, M., and Schreiner, C. E. (1997). Time course of forward masking tuning curves in cat primary auditory cortex. J. Neurophysiol. 77, 923-943.

Brugge, J. F., Reale, R. A., and Hind, J. E. (1996). The structure of spatial receptive fields of neurons in primary auditory cortex of the cat. J. Neurosci. 16, 4420-4437.

Brugge, J. F., Reale, R. A., Hind, J. E., Chan, J. C. K., Musicant, A. D., and Poon, P. W. F. (1994). Simulation of free-field sound sources and its application to studies of cortical mechanisms of sound localization in the cat. Hear. Res. 73, 67-84. doi: 10.1016/0378-5955(94)90284-4

Burger, R. M., Cramer, K. S., Pfeiffer, J. D., and Rubel, E. W. (2005). Avian superior olivary nucleus provides divergent inhibitory input to parallel auditory pathways. J. Comp. Neurol. 481, 6-18. doi: 10.1002/cne.20334

Burger, R. M., and Pollak, G. D. (2001). Reversible inactivation of the dorsal nucleus of the lateral lemniscus reveals its role in the processing of multiple sound sources in the inferior colliculus of bats. J. Neurosci. 21, 4830-4843.

Cai, H., Carney, L. H., and Colburn, H. S. (1998a). A model for binaural response properties of inferior colliculus neurons. I. A model with interaural time difference-sensitive excitatory and inhibitory inputs. J. Acoust. Soc. Am. 103, 475-493. doi: 10.1121/1.421100

Cai, H., Carney, L. H., and Colburn, H. S. (1998b). A model for binaural response properties of inferior colliculus neurons. II. A model with interaural time difference-sensitive excitatory and inhibitory inputs and an adaptation mechanism. J. Acoust. Soc. Am. 103, 494-506. doi: 10.1121/1.421130

Cajal, S. R. (1999). "Anatomo-physiologic considerations about the cerebrum," in Texture of the Nervous System of Man and the Vertebrates: I, eds T. Pasik and P. Pasik (New York, NY: Springer-Verlag), 519-546. doi: 10.1007/978-3-70916435-8 
Carr, C., Shah, S., Ashida, G., McColgan, T., Wagner, H., Kuokkanen, P. T., et al. (2013). Maps of ITD in the nucleus laminaris of the barn owl. Adv. Exp. Med. Biol. 787, 215-222. doi: 10.1007/978-1-4614-1590-9_24

Carr, C. E., and Boudreau, R. E. (1991). Central projections of auditory nerve fibers in the barn owl. J. Comp. Neurol. 314, 306-318. doi: 10.1002/cne.903140208

Carr, C. E., and Boudreau, R. E. (1993). Organization of the nucleus magnocellularis and the nucleus laminaris in the barn owl: encoding and measuring interaural time differences. J. Comp. Neurol. 334, 337-355. doi: 10.1002/cne.903340302

Carr, C. E., Fujita, I., and Konishi, M. (1989). Distribution of GABAergic neurons and terminals in the auditory system of the barn owl. J. Comp. Neurol. 286, 190-207. doi: 10.1002/cne.902860205

Carr, C. E., and Konishi, M. (1988). Axonal delay lines for time measurement in the owl's brainstem. Proc. Natl. Acad. Sci. U.S.A. 85, 8311-8315. doi: 10.1073/pnas.85.21.8311

Carr, C. E., and Konishi, M. (1990). A circuit for detection of interaural time differences in the brain stem of the barn owl. J. Neurosci. 10, 3227-3246.

Chichilnisky, E. J. (2001). A simple white noise analysis of neuronal light responses. Network 12, 199-213. doi: 10.1080/713663221

Coffey, C. S., Ebert, C. S., Marshall, A. F., Skaggs, J. D., Falk, S. E., Crocker, W. D., et al. (2006). Detection of interaural correlation by neurons in the superior olivary complex, inferior colliculus and auditory cortex of the unanesthetized rabbit. Hear. Res. 221, 1-16. doi: 10.1016/j.heares.2006.06.005

Coleman, W. L., Fischl, M. J., Weimann, S. R., and Burger, R. M. (2011). GABAergic and glycinergic inhibition modulate monaural auditory response properties in the avian superior olivary nucleus. J. Neurophysiol. 105, 2405-2420. doi: 10.1152/jn.01088.2010

Cook, D. L., Schwindt, P. C., Grande, L. A., and Spain, W. J. (2003). Synaptic depression in the localization of sound. Nature 421, 66-70. doi: 10.1038/nature 01248

Cook, P. B., and McReynolds, J. S. (1998). Lateral inhibition in the inner retina is important for spatial tuning of ganglion cells. Nat. Neurosci. 1, 714-719. doi: $10.1038 / 3714$

Doubell, T. P., Baron, J., Skaliora, I., and King, A. J. (2000). Topographical projection from the superior colliculus to the nucleus of the brachium of the inferior colliculus in the ferret: convergence of visual and auditory information. Eur. J. Neurosci. 12, 4290-4308. doi: 10.1111/j.1460-9568.2000.01337.x

Drew, P. J., and Feldman, D. E. (2007). Representation of moving wavefronts of whisker deflection in rat somatosensory cortex. J. Neurophysiol. 98, 1566-1580. doi: 10.1152/jn.00056.2007

Ducommun, C. Y., Murray, M. M., Thut, G., Bellmann, A., Viaud-Delmon, I., Clarke, S., et al. (2002). Segregated processing of auditory motion and auditory location: an ERP mapping study. Neuroimage 16, 76-88. doi: 10.1006/nimg.2002.1062

Edut, S., and Eilam, D. (2004). Protean behavior under barn-owl attack: voles alternate between freezing and fleeing and spiny mice flee in alternating patterns. Behav. Brain Res. 155, 207-216. doi: 10.1016/j.bbr.2004.04.018

Fischer, B. J., Christianson, G. B., and Pena, J. L. (2008). Cross-correlation in the auditory coincidence detectors of owls. J. Neurosci. 28, 8107-8115. doi: 10.1523/JNEUROSCI.1969-08.2008

Fischer, B. J., and Peña, J. L. (2011). Owl's behavior and neural representation predicted by Bayesian inference. Nat. Neurosci. 14, 1061-1066. doi: $10.1038 / \mathrm{nn} .2872$

Fischl, M. J., Weimann, S. R., Kearse, M. G., and Burger, R. M. (2013). Slowly emerging glycinergic transmission enhances inhibition in the sound localization pathway of the avian auditory system. J. Neurophysiol. 111, 565-572. doi: 10.1152/jn.00640.2013

Foeller, E., Celikel, T., and Feldman, D. E. (2005). Inhibitory sharpening of receptive fields contributes to whisker map plasticity in rat somatosensory cortex. J. Neurophysiol. 94, 4387-4400. doi: 10.1152/jn.00553.2005

Fujita, I., and Konishi, M. (1991). The role of GABAergic inhibition in processing of interaural time difference in the owl's auditory system. J. Neurosci. 11, 722-739.

Gao, P., Hattox, A. M., Jones, L. M., Keller, A., and Zeigler, H. P. (2003). Whisker motor cortex ablation and whisker movement patterns. Somat. Mot Res 20, 191-198. doi: 10.1080/0899022031000162292

Gollisch, T., and Herz, A. V. M. (2004). Input-driven components of spikefrequency adaptation can be unmasked in vivo. J. Neurosci. 24, 7435-7444. doi: 10.1523/JNEUROSCI.0398-04.2004
Gutfreund, Y., and Knudsen, E. I. (2006). Adaptation in the auditory space map of the barn owl. J. Neurophysiol. 96, 813-825. doi: 10.1152/jn.011 44.2005

Harris, D. M., and Dallos, P. (1979). Forward masking of auditory nerve fiber responses. J. Neurophysiol. 42, 1083-1107.

Hassenstein, B., and Reichardt, W. (1958). "Functional structure of a mechanism of perception of optical movement," in 1er Congres International de Cybernetique 1956 (Paris, France: Gauthier-Villars), 797-801.

Hausmann, L., Plachta, D. T., Singheiser, M., Brill, S., and Wagner, H. (2008). Inflight corrections in free-flying barn owls (Tyto alba) during sound localization tasks. J. Exp. Biol. 211, 2976-2988. doi: 10.1242/jeb.020057

Hubel, D. H., and Wiesel, T. N. (1974). Uniformity of monkey striate cortex: a parallel relationship between field size, scatter, and magnification factor. J. Comp. Neurol. 158, 295-305. doi: 10.1002/cne.901580305

Hyde, P. S., and Knudsen, E. I. (2001). A topographic instructive signal guides the adjustment of the auditory space map in the optic tectum. J. Neurosci. 21, 8586-8593.

Hyde, P. S., and Knudsen, E. I. (2002). The optic tectum controls visually guided adaptive plasticity in the owl's auditory space map. Nature 415, 73-76. doi: 10.1038/415073a

Ingham, N. J., Hart, H. C., and McAlpine, D. (2001). Spatial receptive fields of inferior colliculus neurons to auditory apparent motion in free field. J. Neurophysiol. $85,23-33$.

Ingham, N. J., and McAlpine, D. (2004). Spike-frequency adaptation in the inferior colliculus. J. Neurophysiol. 91, 632-645. doi: 10.1152/jn.00779.2003

Jenison, R. L., Schnupp, J. W., Reale, R. A., and Brugge, J. F. (2001). Auditory space-time receptive field dynamics revealed by spherical white-noise analysis. J. Neurosci. 21, 4408-4415.

Keller, C. H., Hartung, K., and Takahashi, T. T. (1998). Head-related transfer functions of the barn owl: measurement and neural responses. Hear. Res. 118, 13-34. doi: 10.1016/S0378-5955(98)00014-8

King, A. J. (1999). Sensory experience and the formation of a computational map of auditory space in the brain. Bioessays 21, 900-911. doi: 10.1002/(SICI)15211878(199911)21:11<900::AID-BIES2>3.0.CO;2-6

King, A. J., Hutchings, M. E., Moore, D. R., and Blakemore, C. (1988). Developmental plasticity in the visual and auditory representations in the mammalian superior colliculus. Nature 332, 73-76. doi: 10.1038/ $332073 \mathrm{a} 0$

Knudsen, E. I. (1982). Auditory and visual maps of space in the optic tectum of the owl. J. Neurosci. 2, 1177-1194.

Knudsen, E. I. (1983). Subdivisions of the inferior colliculus in the barn owl (Tyto alba). J. Comp. Neurol. 218, 174-186. doi: 10.1002/cne.902180205

Knudsen, E. I. (2002). Instructed learning in the auditory localization pathway of the barn owl. Nature 417, 322-328. doi: 10.1038/417322a

Knudsen, E. I., Blasdel, G. G., and Konishi, M. (1979). Sound localization by the barn owl (Tyto alba) measured with the search coil technique. J. Comp.Physiol 133, 1-11. doi: 10.1007/BF00663105

Knudsen, E. I., and Konishi, M. (1978a). A neural map of auditory space in the owl. Science 200, 795-797. doi: 10.1126/science.644324

Knudsen, E. I., and Konishi, M. (1978b). Center-surround organization of auditory receptive fields in the owl. Science 202, 778-780. doi: 10.1126/science.7 15444

Knudsen, E. I., du Lac, S., and Esterly, S. D. (1987). Computational maps in the brain. Annu. Rev. Neurosci. 10, 41-65. doi: 10.1146/.ne.10.030187.000353

Krapp, H. G., and Hengstenberg, R. (1996). Estimation of self-motion by optic flow processing in single visual interneurons. Nature 384, 463-466. doi: $10.1038 / 384463 \mathrm{a} 0$

Kuba, H., Koyano, K., and Ohmori, H. (2002). Synaptic depression improves coincidence detection in the nucleus laminaris in brainstem slices of the chick embryo. Eur. J. Neurosci. 15, 984-990. doi: 10.1046/j.1460-9568.2002. 01933.x

Kuo, S. P., Bradley, L. A., and Trussell, L. O. (2009). Heterogeneous kinetics and pharmacology of synaptic inhibition in the chick auditory brainstem. J. Neurosci. 29, 9625-9634. doi: 10.1523/JNEUROSCI.010309.2009

Livingstone, M. S. (1998). Mechanisms of direction selectivity in macaque V1. Neuron 20, 509-526. doi: 10.1016/S0896-6273(00)80991-5

Lu, Y., Burger, R. M., and Rubel, E. W. (2005). GABA(B) receptor activation modulates $\mathrm{GABA}(\mathrm{A})$ receptor-mediated inhibition in chicken nucleus 
magnocellularis neurons. J. Neurophysiol. 93, 1429-1438. doi: 10.1152/jn.007 86.2004

Luksch, H., Gauger, B., and Wagner, H. (2000). A candidate pathway for a visual instructional signal to the barn owl's auditory system. J. Neurosci. 20, RC70.

MacLeod, K. M. (2011). Short-term synaptic plasticity and intensity coding. Hear. Res. 279, 13-21. doi: 10.1016/j.heares.2011.03.001

MacLeod, K. M., and Carr, C. E. (2007). Beyond timing in the auditory brainstem: intensity coding in the avian cochlear nucleus angularis. Prog. Brain Res. 165, 123-133. doi: 10.1016/S0079-6123(06)65008-5

MacLeod, K. M., Horiuchi, T. K., and Carr, C. E. (2007). A role for shortterm synaptic facilitation and depression in the processing of intensity information in the auditory brain stem. J. Neurophysiol. 97, 2863-2874. doi: 10.1152/jn.01030.2006

Maier, J. X., and Ghazanfar, A. A. (2007). Looming biases in monkey auditory cortex. J. Neurosci. 27, 4093-4100. doi: 10.1523/JNEUROSCI.0330-07.2007

Marmarelis, P. Z., and McCann, G. D. (1973). Development and application of white-noise modeling techniques for studies of insect visual nervous system. Kybernetik 12, 74-89. doi: 10.1007/BF00272463

Michel, M. M., Chen, Y., Geisler, W. S., and Seidemann, E. (2013). An illusion predicted by V1 population activity implicates cortical topography in shape perception. Nat. Neurosci. 16, 1477-1483. doi: 10.1038/nn.3517

Mori, K. (1997). Across-frequency nonlinear inhibition by GABA in processing of interaural time difference. Hear. Res. 111, 22-30. doi: 10.1016/S03785955(97)00090-7

Mountcastle, V. B. (1957). Modality and topographic properties of single neurons of cat's somatic sensory cortex. J. Neurophysiol. 20, 408-434.

Mrsic-Flogel, T. D., King, A. J., and Schnupp, J. W. H. (2005). Encoding of virtual acoustic space stimuli by neurons in ferret primary auditory cortex. J. Neurophysiol. 93, 3489-3503. doi: 10.1152/jn.00748.2004

Nelson, P. C., Smith, Z. M., and Young, E. D. (2009). Wide-dynamic-range forward suppression in marmoset inferior colliculus neurons is generated centrally and accounts for perceptual masking. J. Neurosci. 29, 2553-2562. doi: 10.1523/JNEUROSCI.5359-08.2009

Netser, S., Zahar, Y., and Gutfreund, Y. (2011). Stimulus-specific adaptation: can it be a neural correlate of behavioral habituation? J. Neurosci. 31, 17811-17820. doi: 10.1523/JNEUROSCI.4790-11.2011

Ohayon, S., Harmening, W., Wagner, H., and Rivlin, E. (2008). Through a barn owl's eyes: interactions between scene content and visual attention. Biol. Cybern. 98, 115-132. doi: 10.1007/s00422-007-0199-4

Payne, R. S. (1971). Acoustic location of prey by barn owls (Tyto alba). J. Exp. Biol. 54, 535-573.

Penfield, W., and Rasmussen, T. (1950). The Cerebral Cortex of Man; A Clinical Study of Localization of Function. Montreal, QC: Macmillan.

Peron, S., and Gabbiani, F. (2009). Spike frequency adaptation mediates looming stimulus selectivity in a collision-detecting neuron. Nat. Neurosci. 12, 318-326. doi: $10.1038 / \mathrm{nn} .2259$

Rauschecker, J. P., and Harris, L. R. (1989). Auditory and visual neurons in the cat's superior colliculus selective for the direction of apparent motion stimuli. Brain Res. 490, 56-63. doi: 10.1016/0006-8993(89)90430-7

Reches, A., and Gutfreund, Y. (2008). Stimulus-specific adaptations in the gaze control system of the barn owl. J. Neurosci. 28, 1523-1533. doi: 10.1523/JNEUROSCI.3785-07.2008

Recio-Spinoso, A., Temchin, A. N., van Dijk, P., Fan, Y. H., and Ruggero, M. A. (2005). Wiener-kernel analysis of responses to noise of chinchilla auditory-nerve fibers. J. Neurophysiol. 93, 3615-3634. doi: 10.1152/jn.008 82.2004

Relkin, E. M., and Turner, C. W. (1988). A reexamination of forward masking in the auditory nerve. J. Acoust. Soc. Am. 84, 584-591. doi: 10.1121/1.396836

Saberi, K., Takahashi, Y., Konishi, M., Albeck, Y., Arthur, B. J., and Farahbod, H. (1998). Effects of interaural decorrelation on neural and behavioral detection of spatial cues. Neuron 21, 789-798. doi: 10.1016/S0896-6273(00)80595-4

Schnupp, J. W., and King, A. J. (1997). Coding for auditory space in the nucleus of the brachium of the inferior colliculus in the ferret. J. Neurophysiol. 78, 2717-2731.

Simons, D. J. (1978). Response properties of vibrissa units in rat SI somatosensory neocortex. J. Neurophysiol. 41, 798-820.

Singheiser, M., Ferger, R., von Campenhausen, M., and Wagner, H. (2012). Adaptation in the auditory midbrain of the barn owl (Tyto alba) induced by tonal double stimulation. Eur. J. Neurosci. 35, 445-456. doi: 10.1111/j.14609568.2011.07967.x

Sivaramakrishnan, S., and Oliver, D. L. (2001). Distinct K currents result in physiologically distinct cell types in the inferior colliculus of the rat. J. Neurosci. 21, 2861-2877.

Slee, S. J., and Young, E. D. (2013). Linear processing of interaural level difference underlies spatial tuning in the nucleus of the brachium of the inferior colliculus. J. Neurosci. 33, 3891-3904. doi: 10.1523/JNEUROSCI.3437-12.2013

Sohn, Y. H., and Hallett, M. (2004). Surround inhibition in human motor system. Exp. Brain Res. 158, 397-404. doi: 10.1007/s00221-004-1909-y

Sovijarvi, A. R., and Hyvarinen, J. (1974). Auditory cortical neurons in the cat sensitive to the direction of sound source movement. Brain Res. 73, 455-471. doi: 10.1016/0006-8993(74)90669-6

Stocker, M., and Pedarzani, P. (2000). Differential distribution of three $\mathrm{Ca}(2+)$ activated $\mathrm{K}(+)$ channel subunits, SK1, SK2, and SK3, in the adult rat central nervous system. Mol. Cell. Neurosci. 15, 476-493. doi: 10.1006/mcne.2000.0842

Stumpf, E., Toronchuk, J. M., and Cynader, M. S. (1992). Neurons in cat primary auditory cortex sensitive to correlates of auditory motion in three-dimensional space. Exp. Brain Res. 88, 158-168. doi: 10.1007/BF02259137

Takahashi, T., and Konishi, M. (1988). Projections of nucleus angularis and nucleus laminaris to the lateral lemniscal nuclear complex of the barn owl. J. Comp. Neurol. 274, 212-238. doi: 10.1002/cne.902740207

Takahashi, T., Moiseff, A., and Konishi, M. (1984). Time and intensity cues are processed independently in the auditory system of the owl. J. Neurosci. 4, 1781-1786.

Takahashi, T. T., Wagner, H., and Konishi, M. (1989). Role of commissural projections in the representation of bilateral auditory space in the barn owl's inferior colliculus. J. Comp. Neurol. 281, 545-554. doi: 10.1002/cne.902810405

Toronchuk, J., Stumpf, E., and Cynader, M. (1992). Auditory cortex neurons sensitive to correlates of auditory motion: underlying mechanisms. Exp. brain Res. 88, 169-180. doi: 10.1007/BF02259138

Torre, V., and Poggio, T. (1978). A Synaptic Mechanism Possibly Underlying Directional Selectivity to Motion. Proc. R. Soc. B Biol. Sci. 202, 409-416. doi: 10.1098/rspb.1978.0075

Ulanovsky, N., Las, L., Farkas, D., and Nelken, I. (2004). Multiple time scales of adaptation in auditory cortex neurons. J. Neurosci. 24, 10440-10453. doi: 10.1523/JNEUROSCI.1905-04.2004

Völgyi, B., Xin, D., and Bloomfield, S. A. (2002). Feedback inhibition in the inner plexiform layer underlies the surround-mediated responses of AII amacrine cells in the mammalian retina. J. Physiol. 539, 603-614. doi: 10.1113/jphysiol.2001.013133

Volman, S. F. (1994). "Directional hearing in owls: neurobiology, behaviour and evolution," in Perception and Motor Control in Birds, Vol. 1994, eds M. N. O. Davies and P. R. Green (Heidelberg: Springer), 292-314. doi: 10.1007/978-3642-75869-0_17

Wagner, H., and Takahashi, T. (1990). Neurons in the midbrain of the barn owl are sensitive to the direction of apparent acoustic motion. Naturwissenschaften 77, 439-442. doi: 10.1007/BF01135947

Wagner, H., and Takahashi, T. (1992). Influence of temporal cues on acoustic motion-direction sensitivity of auditory neurons in the owl. J. Neurophysiol. 68, 2063-2076.

Wang, Y., and Pena, J. L. (2013). Direction selectivity mediated by adaptation in the owl's inferior colliculus. J. Neurosci. 33, 19167-19175. doi 10.1523/JNEUROSCI.2920-13.2013

Wang, Y., Shanbhag, S. J., Fischer, B. J., and Peña, J. L. (2012). Population-wide bias of surround suppression in auditory spatial receptive fields of the owl's midbrain. J. Neurosci. 32, 10470-10478. doi: 10.1523/JNEUROSCI.0047-12.2012

Wehr, M., and Zador, A. M. (2005). Synaptic mechanisms of forward suppression in rat auditory cortex. Neuron 47, 437-445. doi: 10.1016/j.neuron.2005. 06.009

Wilson, W. W., and O'Neill, W. E. (1998). Auditory motion induces directionally dependent receptive field shifts in inferior colliculus neurons. J. Neurophysiol. 79, 2040-2062.

Womack, M. D., and Khodakhah, K. (2003). Somatic and dendritic smallconductance calcium-activated potassium channels regulate the output of cerebellar purkinje neurons. J. Neurosci. 23, 2600-2607.

Zheng, W., and Knudsen, E. I. (1999). Functional selection of adaptive auditory space map by GABAA-mediated inhibition. Science 284, 962-965. doi: $10.1126 /$ science. 284.5416 .962 
Zheng, W., and Knudsen, E. I. (2001). GABAergic inhibition antagonizes adaptive adjustment of the owl's auditory space map during the initial phase of plasticity. J. Neurosci. 21, 4356-4365.

Zhou, Y., and Wang, X. (2012). Level dependence of spatial processing in the primate auditory cortex. J. Neurophysiol. 108, 810-826. doi: 10.1152/jn. 00500.2011

Zhou, Z. J., and Lee, S. (2008). Synaptic physiology of direction selectivity in the retina. J. Physiol. 586, 4371-4376. doi: 10.1113/jphysiol.2008. 159020

Conflict of Interest Statement: The authors declare that the research was conducted in the absence of any commercial or financial relationships that could be construed as a potential conflict of interest.
Received: 18 December 2013; paper pending published: 19 February 2014; accepted: 19 March 2014; published online: 08 April 2014.

Citation: Wang Y, Gutfreund Y and Peña JL (2014) Coding space-time stimulus dynamics in auditory brain maps. Front. Physiol. 5:135. doi: 10.3389/fphys. 2014.00135

This article was submitted to Integrative Physiology, a section of the journal Frontiers in Physiology.

Copyright (C) 2014 Wang, Gutfreund and Peña. This is an open-access article distributed under the terms of the Creative Commons Attribution License (CC BY). The use, distribution or reproduction in other forums is permitted, provided the original author(s) or licensor are credited and that the original publication in this journal is cited, in accordance with accepted academic practice. No use, distribution or reproduction is permitted which does not comply with these terms. 